\title{
Interaction design for supporting communication between Chinese sojourners
}

\author{
Martijn ten Bhömer • Elise van den Hoven
}

Received: 8 March 2011 / Accepted: 12 October 2011/Published online: 2 November 2011

(C) The Author(s) 2011. This article is published with open access at Springerlink.com

\begin{abstract}
In our global village, distance is not a barrier anymore for traveling. People experience new cultures and face accompanying difficulties in order to live anywhere. Social support can help these sojourners to cope with difficulties, such as culture shock. In this paper, we investigate how computer-mediated communication (CMC) tools can facilitate social support when living physically separated from loved-ones in different cultures. The goal is to understand the design considerations necessary to design new CMC tools. We studied communication practices of Chinese sojourners living in the Netherlands and the use of a technology probe with a novel video communication system. These results led to recommendations which can help designers to design interactive communication tools that facilitate communication across cultures. We conclude the paper with an interactive communication device called Circadian, which was designed based on these recommendations. We experienced the design recommendations to be abstract enough to leave space for creativity while providing a set of clear requirements which we used to base design decisions upon.
\end{abstract}

Electronic supplementary material The online version of this article (doi:10.1007/s00779-011-0482-1) contains supplementary material, which is available to authorized users.

M. ten Bhömer $(\square) \cdot$ E. van den Hoven

Department of Industrial Design, Eindhoven University

of Technology, P.O. Box 513, 5600 MB Eindhoven,

The Netherlands

e-mail: m.t.bhomer@tue.nl

E. van den Hoven

e-mail: e.v.d.hoven@tue.nl
Keywords Human-computer interaction ·

Computer-mediated communication - Interaction design . Design recommendations - Cross-cultural communication . Culture shock

\section{Introduction}

The field of computer-mediated communication (CMC) studies communication that occurs between human beings via the instrumentality of computers with the goal to enhance communication by spanning spatial and temporal distances [1]. CMC can be considered as an extension for human beings to maintain person-to-person relationships without being limited in geographical location.

The term global village describes the concept in which technology diminishes spatial distance because information can flow instantaneously from one location to another. When this phrase was coined by media philosopher McLuhan [2], the world was on the verge of globalization. Currently, globalization is here, many multinational companies have increased the deployment of expatriates [3], and the number of international student enrolments are higher than ever [4]. The leading actors in globalization are sojourners: betweensociety culture travelers, e.g., exchange students and business expatriates. A sojourn is a voluntary temporary stay as most sojourners expect to return home after the completion of their assignment, contract or studies [5]. Transitioning between cultural environments can have consequences for the well-being of the sojourner. For example, culture shock can cause "anxiety that results from losing all our familiar signs and symbols of social intercourse" [6, p. 1]. One of the important coping mechanisms for preventing a cultural shock is social support [7]. Social support can come from various sources: host-country nationals (people with whom 
the sojourner enters into contact), home-country nationals (other sojourners from the same cultural background) or home-country relatives (relatives living in the home country) [5]. Social support from home-country relatives is important for the sojourner because it can help to maintain ethnic loyalty and provide tangible and emotional support [8]. Simultaneously, it is likely that existing relationships with relatives will be put under pressure when the sojourner is distressed [5]. It is even possible that being immersed in a different culture can have an effect on one's own cultural identity [9].

The aim of this paper is to investigate how novel CMC tools can facilitate social support between the homecountry relative and the sojourner, by: (1) identifying the challenges caused by the cultural distance between the sojourner and the relative in the home country, (2) investigating the consequences of new interactive communication tools on the communication practices for the sojourner and the relative and (3) providing a set of recommendations to design specifically for facilitating social support and presenting an design of an interactive communication tool based on these recommendations. These three research phases are visualized together with the research scope which converged during the process in Fig. 1.

We focus our analysis on Chinese dyads composed of young (aged 20-30) Chinese sojourners living in the Netherlands and the communication with their parents. We selected this target group because Chinese sojourners face a large cultural distance when moving to the Netherlands. In addition, the relationship of Chinese children with their parents is complicated. These children have to show filial piety (devotion and respect for parents and one's family throughout their entire life) based on cultural normative expectations [10]. In the following section, we present the theoretical background regarding these two cultures and their communication practices.

\section{Related work}

We are interested in the design lessons we can draw based on the theory of several disciplines. Anthropology can provide insights in the theory behind cultural values and the resulting consequences for communication and CMC tools. Social sciences studied the communication practices of family members living separated from each other. Finally, we will analyze several applications and studies of family communication and awareness systems from the fields of human-computer interaction (HCI) and interaction design.

\subsection{Cultural differences}

Hofstede describes culture as "the collective programming of the mind that distinguishes the members of one group or category of people from another" [11, p. 9]. One of the important visible manifestations of culture are rituals [11]. Rituals are collective activities that are technically unnecessary to the achievement of desired ends, but that within a culture are considered socially essential. Cultural individualism or collectivism (IC) has a direct influence on behavior of people through norms and rules used in daily life. Individualistic cultures emphasize the goals of the individual over group goals, whereas collectivistic cultures stress group goals over individual goals [12]. Hofstede discovered that the Netherlands has a high Individualism Index (IDV), meaning it is a highly individualistic culture. China, on the other hand, has a relatively low IDV score [11], indicating China to be a highly collectivist culture. Even though Schwartz [13] used a different set of cultural values he confirms Hofstede's. These differences in cultural IC between China and the Netherlands could be the potential cause of culture shock for a Chinese sojourner in the Netherlands.

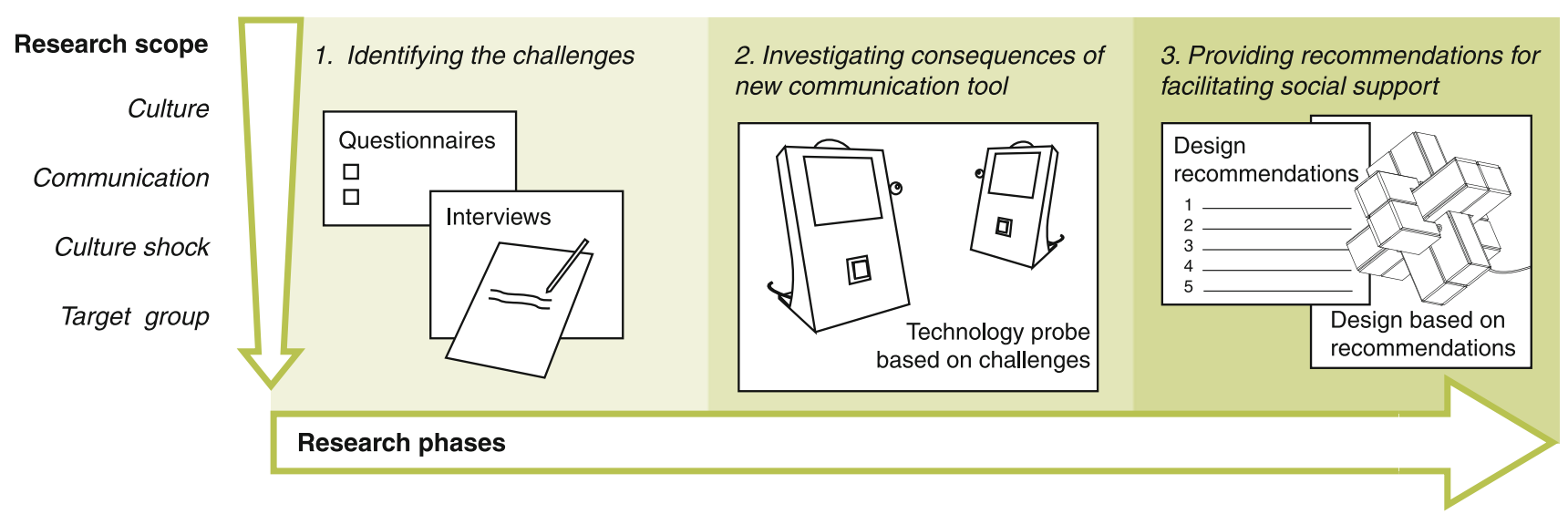

Fig. 1 Overview of the converging research scope and the three research phases 
Another difference between the Dutch and Chinese culture lies in their communication styles [14]. One way to explain variations in styles across and within cultures is Hall's [15] differentiation between high-context (HC) and low-context (LC) communication. In general, cultures that favor LC communication will pay more attention to the literal meanings of words than to the context surrounding them. On the other hand $\mathrm{HC}$ cultures pay more attention to non-verbal and paraverbal cues, for example body language, intonation in voice and other knowledge which one has in common with the communication partner.

LC communication is used mostly in individualistic cultures, whereas HC communication is used mostly in collectivistic cultures [16]. The Netherlands is considered an LC culture. This means that the speaker or writer is responsible for communicating the message in a direct, loud-and-clear way that does not rely on previous, external or unstated information. In $\mathrm{HC}$ cultures like China, it is up to the listener or reader to figure out what the speaker or writer is trying to say. HC listeners and readers need to have additional background knowledge that most members of the culture or group are expected to already know.

\subsection{Culture and computer-mediated communication}

In recent years, there has been a growing interest in studies examining cultural issues in CMC $[10,17,18]$. An analysis of this field concluded that it is hard to identify explanatory themes or frameworks, and often contrary results are yielded [19]. The studies are often focused on collaboration in the work context and therefore aim for the least amount of collaborative effort. However, for Chinese communication partners, their culture dictates the building and maintenance of relationships in addition to completing the communication task at hand [20]. This desire has been recognized, and allowing the user to promote or minimize emotional information is now considered as an additional goal for CMC collaboration [19].

Media richness refers to the extent to which a communication tool provides contextual support for interaction, for example by communicating body language, facial expressions and tone of voice [21]. Richer media such as video conferencing have more of these features than leaner media such as Instant Messaging. In a study comparing the effects of media richness for the interpersonal communication between high-context Chinese dyads and low-context American dyads, there were few cultural differences found [17]. But it was concluded that for the Chinese pairs, visual awareness was significantly more socially fulfilling than for the low-context pairs because of the availability of high-context information.
Chinese CMC users make very deliberate choices about how to use media qualities to both convey and mitigate emotional information depending on which is most appropriate to the situation and the relationships [17]. Chinese exchange students and their family perceive phone communication as a more suitable medium to convey emotional information than email because it is easier to express personal views and feelings using additional audio information [10].

\subsection{Family communication}

Communication tools should help families to fulfill social obligations in a way that does not create new obligations, it is important to maintain the family interactions that people find special [22]. For families who encounter cross timezone communication time-distance poses more challenges than geographical distance. Members of separated family's rely mostly on synchronous communication because asynchronous communication is perceived as a method to exchange formal information and messages [23]. Routines and rituals are powerful organizers of family life which support its stability during times of stress and transition [24]. In cross time-zone family situations, communication is still based on implicit routines, which means that a regular time window is informally recognized by both parties as a time to communicate [23]. Another important element of long-distance communication is the facilitation of emotion and problem sharing. This should be facilitated in a subtle way while also giving the opportunity to comfort the remote partner [25].

Awareness systems "support individuals to maintain, with low effort, a peripheral awareness of each other's activities" [26, p. 1351]. Awareness systems in the home and personal setting can benefit from affective awareness [26] (the general sense of being close to one's family and friends). Good examples of using peripheral awareness to support emotional relationships are Gaver's well-known feather, scent and shaker concepts [27]. The ASTRA system is an awareness system which addresses a need of families currently unmet by other systems: serendipitous sharing of moments through the day [28].

Summarizing, the above-mentioned insights provide a theoretical understanding of cultural differences and communication practices. There are distinct cultural differences between China and the Netherlands, as well as in their communication styles. The studies about CMC tools and cultural backgrounds show that emotional awareness is important for the target group and that richer media lead to a greater social fulfillment. The studies about communication between separated family members show that there are interesting design opportunities for new communication tools. 


\section{Investigating communication practices}

Based on the literature, we identified the challenges and opportunities of communication across cultures. Through user studies, we aim to gather more understanding in the influences of the new cultural environment on communication practices between the sojourner and relatives in China. We will present the results of a questionnaire study and a qualitative interview study conducted with Chinese sojourners in the Netherlands.

\subsection{Questionnaire study}

The goal of the questionnaire study is to investigate whether there are correlations between the degree of culture shock and the amount of affective awareness the participants are currently experiencing. We aimed the questionnaire at current voice communication experiences of the sojourners with their parents in China.

We chose to design an online questionnaire, assuming we would have easier access to our Chinese target group. We used 30 questions from the Affective Benefits and Costs of Communication questionnaire to quantify the affective awareness [26]. To measure the degree of culture shock, we used the seven questions of the culture shock questionnaire [29]. We directed the questionnaire to Chinese people living in the Netherlands with parents in China. The questionnaire was distributed by a Chinese organization in the Netherlands and an online discussion group for Chinese people in the Netherlands. Fifty-four people filled in the questionnaire from which we eliminated 22 results because of missing data. From the resulting 32 participants, the largest amount of people $(87.5 \%)$ was between 20 and 30 years old. Exactly $50 \%$ was male and $50 \%$ was female; $46.9 \%$ of the participants were students, $34.4 \%$ was working, $12.5 \%$ was searching for a job, and the remaining $6.2 \%$ had a different occupation. The durations of the sojourn of the participants were diverse: the largest groups were 1-2 years in the Netherlands (31.3\%) and $3-5$ years in the Netherlands $(28.1 \%)$.

The female participants reported a higher level in the "sharing experiences" theme of the questionnaire (significant with Pearson correlation $r(32)=0.39, p<0.05$ ). This theme includes the notion that experiences can be shared mutually from both sides (the participant and the parents). The "expectations" theme includes the feeling that the parent should contact the participant regularly and the disappointment if the parent does not contact the participant. The participants have increasing expectations of their parents contacting them when they are longer in the Netherlands (significant with Pearson's correlation coefficient, $r(32)=0.36, p<0.05)$. An examination of the degree of culture shock and the themes of affective awareness resulted in the observation that the theme "thinking about each other" negatively relates to culture shock (Pearson's correlation coefficient, $r(32)=-0.45$, $p<0.01)$. This means that when the participants experience a higher degree of culture shock, they will think less about their parents.

\subsubsection{Discussion}

Female participants report a higher value in the "sharing experiences" theme, which would indicate that the male participants from this study have more difficulties to share experiences with their parents. The result that participants expect their parents to contact them more the longer they live abroad is surprising. A possible explanation could be that the role of the person who initiates the communication session changes. Parents are getting used to the fact that their child is living away from them and are less active in communicating with their child. The child still has the expectation that the parent initiate the contact with him or her, but this expectation is not addressed to the parent. The result of the negative correlation of culture shock with the "thinking about each other" theme seems to contradict with these expectations because the study shows that the participants will think less about their parents when they have a higher degree of culture shock. It could be the case that the participants do expect more contact from their parents, but will not show this due to the unease caused by culture shock. Parents could fail to recognize this symptom, and as a result, the communication between parent and child cannot provide the social support necessary to cope with culture shock. If this is true, there could be an opportunity in providing a better communication channel between parent and child so that it becomes more apparent for the parent that the child is in need of contact.

Based on the issues that were raised by the questionnaire study, it is clear that there are still unanswered questions regarding the influence of culture shock on communication and the problems this is causing.

\subsection{Interview study}

To gain a better explanation from the insights of the questionnaire study, we decided to conduct an interview study. We used a semi-structured interview technique with prepared questions on the topics of: communication with the participant's parents, communication content, cultural differences and communication and routines.

Participants for the interviews were approached with the help of a Chinese organization in the Netherlands. The sample existed from four participants: three females and one male. The age varied from 23 to 27 . One participant lived in the Netherlands for 7 months, one for 1.5 year, the 
two other participants for 5 and 6 years. Three of the participants were working, and one participant was a student. The participants received a voucher of 7.50 euro for their effort. To analyze the interviews, we applied the affinity diagram technique [30]. We transcribed the audio recordings of the interviews and wrote down relevant quotes on post-it notes. These post-it notes were re-grouped into themes. Finally, we used the contents of the themes to draw conclusions for every theme.

All the participants described that the communication window was based on the available time. Communication moments during weekdays were short and in-between activities, in the weekends the participants had more time to communicate with their parents. Time difference was not perceived as a problem, but as something they could plan around. P4 explained: "That's not a very big issue. I know the time difference very well because of my job". The frequency of communication and amount of involvement is personal and not the same for every participant. These rituals seem to vary depending on how long the participant is living in the Netherlands. P3 (who lived in the Netherlands shortest) called every evening with her mother. P4 calls short during weekdays, while having long communications sessions in every weekend. P1 and P2 both report that after 2 years they called less frequent with their parents, the ritual was lost because of other activities in the Netherlands. But both started their communication ritual again in which they call once a 2 weeks during the weekends.

The participants described different methods of how their parents used contextual information to create high-context communication styles. P3 described for example how their online/offline status on internet was noticed by their parents: "I go online on MSN, and then my mother asks "why are you at home today, why don't you go to school, or go to work' and I say 'it is holiday here"'. Other methods that the participants mentioned during the interviews were the sound of the voice, or the kind of questions their parents asked them. Information was also transferred through other people. The family of P1 in the Netherlands gave information to the parents in China, which was then discussed in direct conversations. The feeling of being connected is more important than the topic of conversation. The conversations are often started with very mundane questions, as $\mathrm{P} 4$ puts it: "How is your health, did you eat well recently? These are very typical Chinese questions." Being positive in the communication between the participants and parents is something which came up in every interview. It is important for the participants that they give an impression that everything is going well and that their parents do not have to be worried. P1 mentions: "I also talk to them. But most of the time I say positive things. If I say a lot of negative things they will probably worry about me more."

In some of the interviews, the influence of cultural differences on the behavior of the participants was mentioned.
P1 specifically mentions the effect of culture shock and the reason why she would not share her feelings with her parents: "The first 2 years for me were really hard because I had to get used to the culture, also I was busy with my study. When I had a problem I never told my parents only the positive things." P3 talked about the effects of a different cultural environment on her behavior. When she went back to China she had problems with buying things because she was not used to a farmers' market anymore. She recalls a conversation with her friends about this: "They asked me: 'Can you buy this at the market?' And I was so sure, of course I can. 'Can you check the price or can you check if it is fresh?' And then I started thinking, I cannot indeed." In the interviews, the participants mentioned that their parents were aware of the cultural differences between the Netherlands and China. The parents of P3 supported her specifically for this reason: "She (participant's mother) thinks it is good for me because I can understand different cultures and differences between Asia and Europe." $\mathrm{P} 4$ tells about his difficulties of explaining cultural differences to his parents: "From time to time I will try to explain something to my mother or my father. I will tell them that this is just the culture, I cannot do anything about it except getting used to it." From all these different statements, it becomes clear that cultural differences are an important element in the communication between the participants and their parents, and they all have different methods of coping with these differences.

\subsection{Summary and discussion of findings}

In this section, we will summarize our five most important findings regarding the communication practices of Chinese sojourners in the Netherlands.

\section{Parents' need of $\mathrm{HC}$ communication}

In collectivist cultures such as China, a high-context communication style is preferred. Chinese parents found opportunities to maintain elements of this high-context communication style. However, their children did not. We assume there are various explanations. Firstly, the child may not have the right tools to be able to engage in such communication style. Secondly, the preferred communication style of the child could have changed because of living in a culture with a different communication style. And finally there is also the possibility that the child is not interested enough in the life of the parents to engage in a form of high-context communication which costs more effort than low-context communication.

\section{Failing of routines and expectations}

Connectedness is very important for both the parent and the sojourner. The participants indicated that they 
communicate frequently and regularly using direct synchronous communication. These communication sessions can be seen as routines for the sojourner and parent because they take place on a fixed day and time in the week. If this routine cannot be followed, for example because of other obligations, the other party will be worried. The two participants who were living in the Netherlands for 5 and 6 years both described that they have had a "communication dip" because of a more active lifestyle. Later their lives became more stable and they formed new communication routines (less frequent than in the beginning). The questionnaire study showed that over time the children's expectations of the parents contacting them increased. This could be contributed to the absence of communication routines during the "communication dip". The parents lost the awareness of when to call their children because they were not up-to-date about their daily lives.

\section{Desire for connectedness on opportune moments}

The participants indicated that they could adapt well to the time-windows available for communication. For most of the participants, this meant that they called during lunch breaks for short updates and used the mornings in the weekend for longer conversations. However, these communication routines are a result of the time difference and limit both the parent and the child in communication opportunities. Some participants mentioned during the interviews that they had to make efforts to give an update to their parents when they could not follow the communication routine as normal because of different activities. The cause behind these routines is the use of synchronous communication means by all the participants. Participants indicated that they like these means. The children mentioned during the interviews that hearing their parents' voice made them feel more connected and the direct synchronous communication made them feel like they were really together.

\section{Explicit and implicit communication of culture}

One of the goals of the studies was to find out more about how the parents and children deal with differences in culture in communication and if this is an important topic of communication. Cultural exchanges through communication between parent and child occurred. This happened mostly when there were special events which the children experienced, for example Queen's Day (Dutch national holiday) or Christmas. The participants also mentioned during the interviews that the parents noticed cultural events in the Netherlands through their communication routines. For example during the weeks in May and June, the children communicate more during weekdays because of national holiday days.
5. Being positive and culture shock

An unexpected insight from the study has to do with the experiences which the children decide to not share with their parents. All participants mentioned that they do not share problems and bad experiences with their parents. It is important for the participants to remain positive in the communication and to show that they are doing well. The children do not want to make their parents worried, but show instead the good things and their ability to live an independent life. This can be linked to the result of the questionnaire. In this study, it was shown that the sojourners thought less about their parents when they experienced a higher degree of culture shock. A reason could be that because of the difficulty to talk about problems in daily life, their parents cannot provide enough social support during the times when culture shock is highest. In normal Chinese life, these signals will be conveyed implicitly using high-context communication, but with the lack of $\mathrm{HC}$ information, it is difficult for the parents to be aware of the problems of their child.

\section{Technology probe: Videomail}

To help transferring the knowledge gathered through the user studies into a set of design recommendations, we decided to apply the technology probe approach [31]. This approach is suitable for gathering information about the users and use of technology in the real context, to trigger users to think about new uses of technology and to reflect on their communication practices. The technology probe named Videomail is a device which can be used to record short video messages for the communication partner who

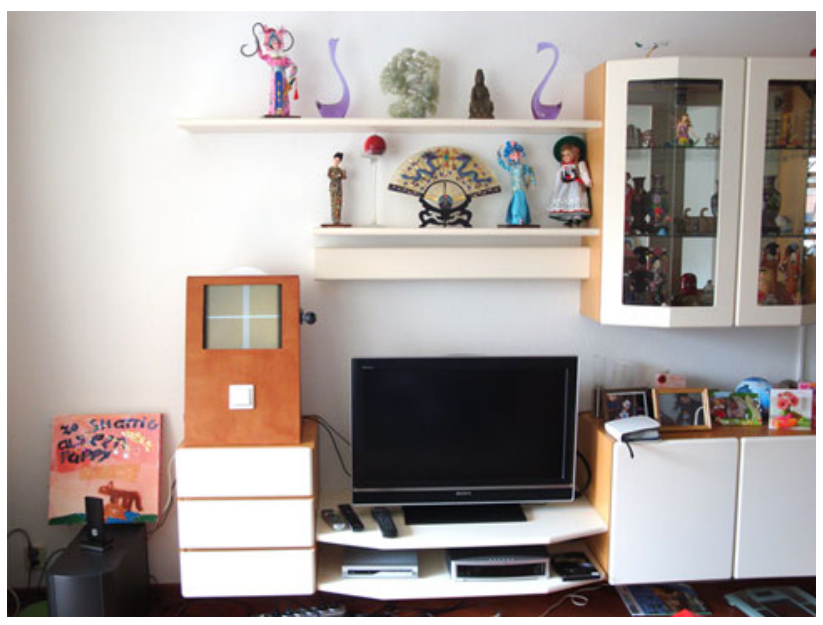

Fig. 2 The Videomail device is located on the cupboard next to the television in the home of one of the participants 
also has a Videomail device (Videomail is shown in Fig. 2).

\subsection{Design}

The goal of the design of the technology probe was to build further upon the results of the questionnaire and interview studies which were described in Sect. 3.3. We will first explain how these five findings were translated in the technology probe.

During the interviews, we noticed that both the parents and the children had different requirements of context within their communication. Parents used many sources to acquire high-context information, while the children relied less on high-context during communication. The related work about culture and computer-mediated communication (Sect. 2.2) indicated that media richness and context are closely related and context is an important factor to enable socially fulfilling communication between Chinese dyads. With the technology probe, we aimed at discovering how the two communication partners will use context when they both have the availability of richer media. We decided to use video messages since these afford both low- and highcontext communication.

The activities and schedule of the sojourner can change rapidly and are dependent on the phase within the sojourn. When the life of the sojourner becomes more filled with activities, it is difficult for the sojourner and the communication partner to initiate and maintain communication routines. With the technology probe, we wanted to test whether an interactive communication tool will be able to convey an awareness of each other's daily lives and will influence the communication routines of the communication partners. We decided to base the interface on a timeline to test how important time is for the communication partners' awareness of each other's daily life routines. Video messages are placed on the corresponding location on the timeline (the timeline interface is showed in Fig. 3). We added a rotating disk on top of the object (illustrated in Fig. 4) which the user can manipulate to scroll through the timeline. Recording a video message is an activity which can be executed quickly without paying too much attention to the interface or the controls. The webcam on the side of the Videomail device (illustrated in Fig. 4) starts recording when the switch in the middle of the front panel is pushed. When the switch is pushed again, the webcam stops recording. The video messages appear on the timeline of the communication partner who can view the messages on a moment suitable for him or her. Viewing the messages can be done by scrolling the timeline left or right. When the video is located in the vertical bar (the vertical bar is visible in Fig. 3) and the user pushes the switch, the message will play. We choose to combine the playback and the

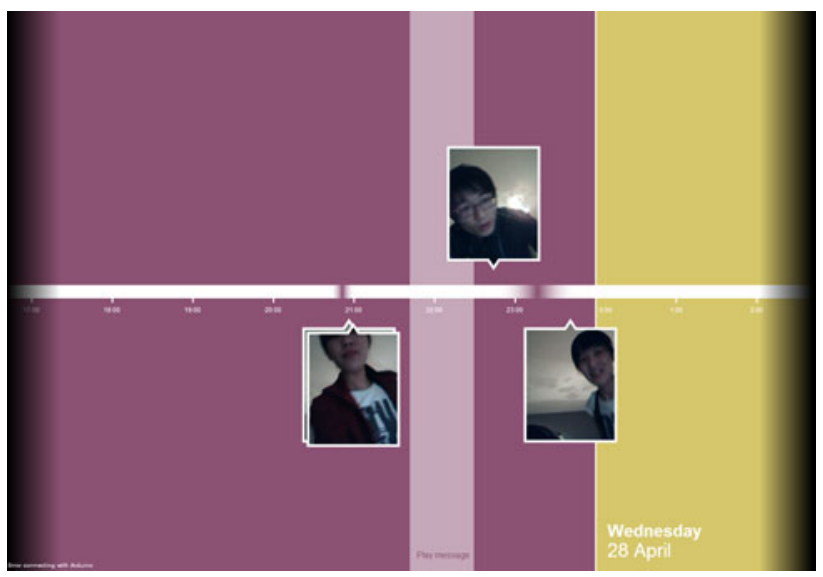

Fig. 3 Timeline interface with received video messages mapped on the day

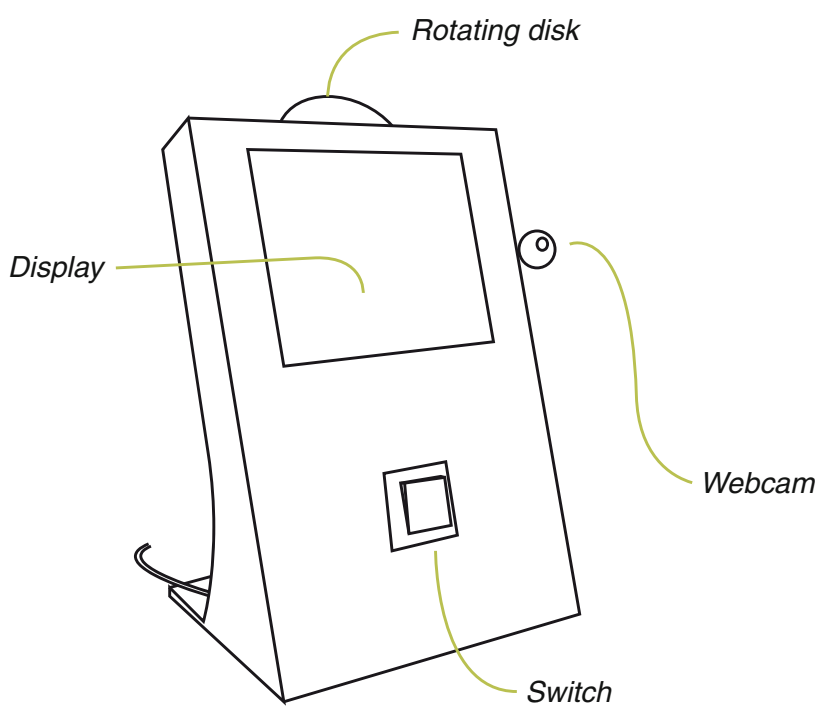

Fig. 4 Hardware elements of the Videomail device

recording of video messages at one location in order to offer the user one communication channel which couples both perception and action at the same location.

The interview study participants mainly use synchronous communication tools to communicate with each other. The sojourners indicated that they like to hear each other's voices, have the direct connection and feel being close together. On the other hand, the sojourners reported that this did not leave much room for flexibility which is required to be connected on more opportune moments. Asynchronous communication tools are often lean in media qualities which could be a reason they are not favored by sojourners. For Videomail, we chose to use asynchronous video messages because we want to trigger the sojourners to think about this type of communication in relation to their current communication tools. We also wanted to investigate the responses from the sojourner and 
communication partner when asynchronous tools enabled richer medium qualities.

An interesting observation from the user studies was that much information about the new culture was communicated explicitly through the communication of daily routines and rituals (for example the online/offline status on internet). One of the goals of Videomail was to build in opportunities for more of such explicit communication of culture through daily routines. We created a kiosk-shaped communication device which affords to be placed on a fixed location within the homeenvironment. Because the device cannot be easily moved, we expected that the routines related to the location of the object are going to be reflected in the communication routines. The timeline with the recorded messages will be the representation of these routines because they combine location, time and rich media qualities.

The sojourners who participated in the questionnaires and interviews were aware about the information they filtered and what they communicated to their parents. It is for example important for them to show a positive image about their experiences. From this, we can conclude that it is important that both communication partners can control what is communicated and how they communicate it. Because of this, we chose for clear affordances of the device. The device would not automatically record messages, but the communication partners can choose themselves when to record something and send it.

\subsection{Testing Videomail}

After a 1-week pilot run, we resolved some stability issues, added the option to display multiple messages, and we prepared the technology probes for deployment. The goal of the test was to approach the real-life situation as much as possible, including the target group: Chinese sojourners in the Netherlands with parents in China. Because it was not possible to deploy the technology probes in China, we chose for participants both located in the Netherlands. However, they do share a similar kinship as the intended target group. Our participants were a Chinese dyad composed from a Chinese woman in the Netherlands who is living and working in Eindhoven (P9) and her aunt (a Chinese relative) who is living in Nijmegen, the Netherlands (P8). They do not meet regularly but keep in touch through voice communication. We deployed the two technology probes in both households. The participants chose a place for the Videomail device. After connecting the prototype to the wireless network of the participant, the functionality of the device was explained. We did not brief the participants about the background of the technology probe or the type of video messages they could send. Both participants understood the functionality of the device quickly and made a first test message directly. Figure 2 shows the Videomail device in one of the participants' living rooms. After 1 week of using the system, we

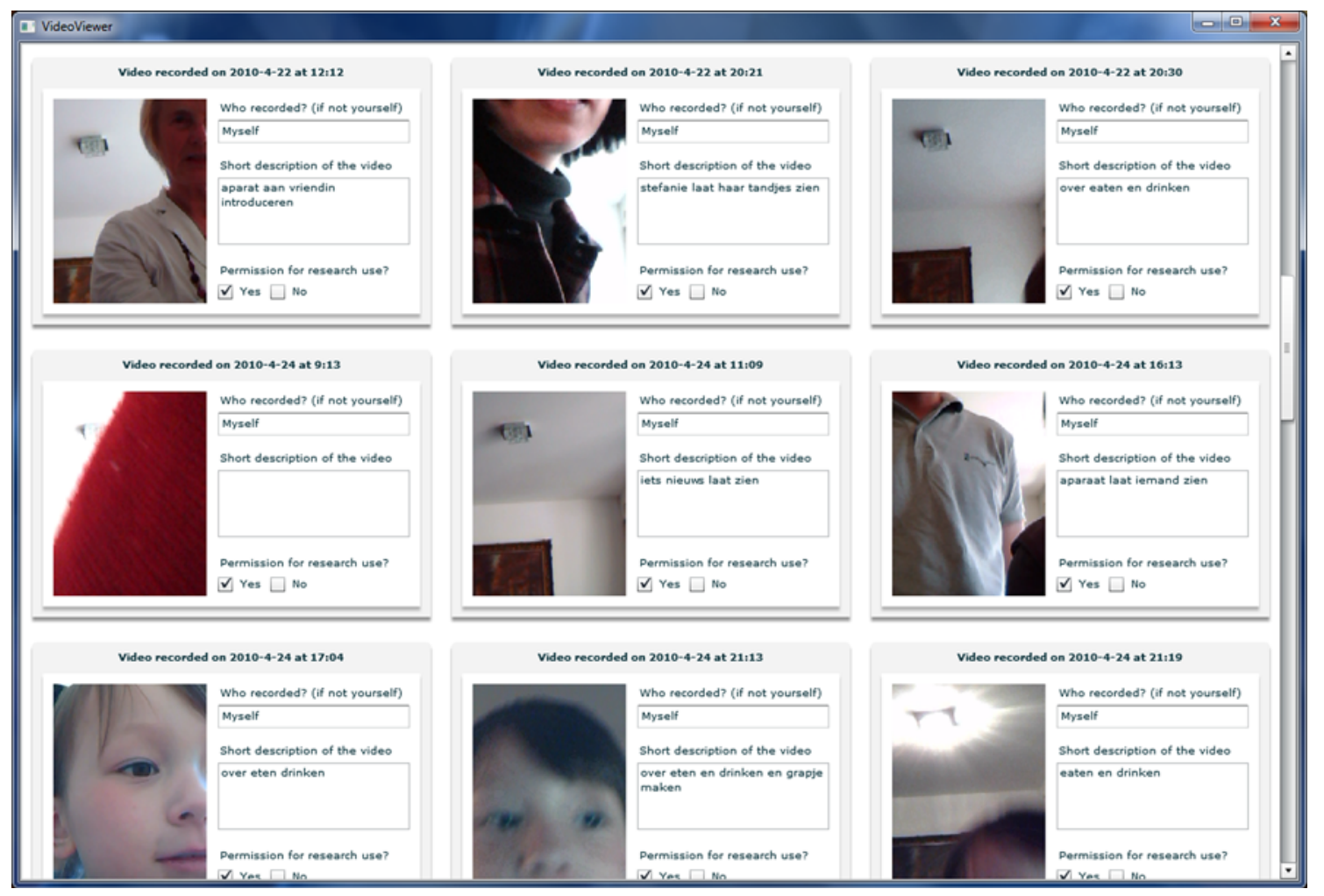

Fig. 5 Digital form for consent and message description 
collected the technology probes in both locations. We debriefed the participants by interviewing them about their experiences of using the Videomail device. We also gave both participants the opportunity to complete a digital consent form (showed in Fig. 5) on which they could approve individual video messages to be reviewed later by the researchers. The other video messages were deleted immediately after the test. P8 has sent a total of 45 messages and gave consent over $71.1 \%$ of the messages. P9 has sent 23 messages in total and gave consent over $26.1 \%$ of the video messages. A possible reason for this low percentage could be that the partner of P9 also used the Videomail to send messages but rather not participated in the experiment.

\subsection{Results and conclusions Videomail deployment}

One assumption that led to the design of this system was that the communication of daily routines will enable a sense of awareness of each other's daily life. Messages were sent when coming back from work, when having dinner or when going to sleep. The debriefing interviews with the participants confirmed the finding that this created an awareness of daily life. P9 mentioned "I know when they come back home, sometimes when they are going to eat and when they go to sleep if they send a message: more about their daily life. Also which clothes they are wearing". An analysis of the messages that were sent during this experiment showed that many messages indeed communicated mundane daily information. Three types of messages could be distinguished: short greetings, status updates and questions. The short greetings did not contain much information, for example just a "good morning" or "good night". The status updates contained more information, for example about an activity which was done that day or was planned. The questions were messages in which information was asked of the other person.

We assumed that the ability to create asynchronous messages would be valuable when having a small communication window because of time differences. This situation was difficult to simulate in the experiment. A critique on an asynchronous communication system could be that the communication window becomes "spread-out" and people have to pay more attention to see whether there are new messages. Related to this, P8 describes the following experience: "I looked to see if there are new messages or not. When there was a new message, I always wanted to see it immediately."

On the other hand, the asynchronous communication can help to feel more connected but also to consider and respect the other's personal life. P8 mentioned: "You feel the distance with the person is a lot smaller. If you call you are never sure, is the other person happy, maybe they do not want to talk to you at that moment. But with this one you can click and it does not matter." Even without a time difference, the participants experienced the asynchronous messages to be pleasant because it lowered the threshold to communicate more regularly with each other.

The participants, both in the pilot test as in the deployment, loved to see each other. It gave additional information which could enable high-context communication. There were some examples in the debriefing interviews which gave the idea that the participants noticed the potential of asynchronous messaging. P8 recalled "Sometimes, when I felt I wanted to say something I could just do it. You can decide to contact somebody on your own terms, and that is very practical." She also reflected on how this could help communication between her and her parents and was enthusiastic about this possibility.

The timeline interface was created based on the recommendation from theory that it is important to provide a temporal context to enable people to have a better idea of each other's daily activities. This interface did not cause any problems and was clear for the participants. However, certain aspects could be improved, e.g., the ability to view back earlier movies should be easier, and we should add notifications of new messages. Also the layout and the colors could be adapted more to the physical design of the object and the domestic environment.

Another decision was to design Videomail as a kioskshaped object. The interaction was open for everybody who wanted to interact with the object. We chose for this approach because of the goal to create an interaction style which would trigger short daily messages. We do think that in the long run, this openness can cause some privacy issues. During the experiment, it happened that visitors came into the house and started to interact with the object. P8 explained during the debriefing interview that many of her friends were interested in the product. Because of the large form factor, people could not miss the product that was standing on a prominent place in the living room (next to the television in Fig. 2). P8 explained: "people were very curious! 'Oh, what is this, did you buy this?" P9 explained that she did not know most of the people who visited her aunt and sent messages. But meeting those people gave her a peek in her aunt's life she normally would not get. In this case, this caused no problems because the messages were not intimate. For future designs, the messages themselves could be more "hidden" in the object and require clear permission by the owner for playback.

\section{Design recommendations}

The following design recommendations are meant for designers who are developing an interactive communication tool for family members who are living separated from 
each other in different cultures. Social support can be facilitated by enabling communication styles more suitable for the cultural background of the sojourner and by conveying details about a culture which normally would not be communicated intentionally by the individual sojourners.

The following five recommendations will be explained in more detail: how to describe the target group (Sect. 5.1), how to use context in communication (Sect. 5.2), why routines should be communicated (Sect. 5.3), which aspects for the interaction with such a tool to consider (Sect. 5.4) and implications of the design recommendations when implemented in an interactive communication tool (Sect. 5.5).

\subsection{Target group}

It is necessary to have the right tools to describe and specify the target group. Theories provide an abstract level of understanding, while qualitative studies can give detailed insight in the life of the target group. Hofstede's theory of cultural dimensions [11] can be used to assess the cultural distance is between the home country and the new country. The dimension individualism versus collectivism can be an important factor, this determines whether a person favors group goals over individual goals or vice versa. It is important to consider that these theories describe a country's national culture, it is always possible that values of an individual are very different. The experience of the sojourner can be described by using the theory of culture shock [5], this phenomenon can be measured by using the culture shock questionnaire [29]. To empathize and understand the people from the target group, qualitative studies such as focus groups and interviews on location are especially valuable to generate insights. It is important to have an idea of which target group to approach beforehand. If possible try to investigate both parties of the target group: the sojourner and the communication partner(s) in the home country. Some aspects to keep in mind are: the difference in cultural values between the home culture and host culture of the sojourner, the time difference between the two countries, the sojourning experience of the sojourner, the expected duration of the sojourn, experience of the sojourner with different cultural values and previous life experience of the sojourner.

\subsection{Context}

An important element in communication is the availability of context for the sojourner and communication partner. Context can be provided using a communication tool, but this is influenced by the preferred communication style of the sojourner, the methods a sojourner is already using and the different types of context which are available.
The amount of context which needs to be shared depends on the communication style. People in collectivistic cultures will generally favor high-context communication styles, while people from individualistic cultures will favor low-context communication styles. It is important to realize that people always try to adapt their communication tool to the communication style they prefer. From the interview study, we discovered for example that parents who send money to their children can see their spending patterns, also monitoring the on- or off-line status on an instant messaging program can give valuable information. Based on the interview studies and insights from theory, we propose some examples of context which could be considered for communication.

1. Implicit awareness information which could say: "thinking of you", for example the feather, scent and shaker concept [27].

2. Using time to indicate when an event happened, for example by delivering messages on the same time as in the remote time-zone.

3. The location of the communication, which can be precise (e.g. indicate the room in the house) or broad (e.g. which city).

4. The well-being of a person can give very personal contextual information, for example by communicating stress levels.

5. Communicating the social interactions which a sojourner undertakes in the new culture can give contextual information from a different perspective.

6. Knowing when and how a person does certain daily activities can communicate context about (cultural) activities.

\subsection{Routines}

Rituals are one of the visible manifestations of cultural values. A sojourner might (unconsciously) pick up some of the rituals in the host culture and use them in his or her own routines. Comparing the routines of the sojourner with the routines of the communication partner in the home culture can create awareness for both. When families are living together, routines and rituals are important for family organization. When a sojourner is detached from his or her family, it is desirable that an interactive communication tool affords the maintenance and creation of routines. The sojourner and communication partner rely mostly on communication routines which are shaped during the sojourn. When changes in lifestyle occur and these routines fail, it takes time to adapt. By communicating each other's routines, it can be easier to adapt to changes in lifestyle. The interactive communication tool should allow the sojourner to compare his or her routines with the routines 
of the family member in the home country and vice versa, for example by comparing the moments on which routines took place or messages were sent. A possible implementation is to use a timeline which shows the day of the communication partner with activities and communication events.

\subsection{Interaction}

It should be well considered how much control the user has about what is shared by balancing between what is shared actively and passively. The object should be discrete enough to respect the privacy of the users, for example by hiding personal information from direct visibility. To enable the sojourner to communicate routines and context, it is necessary that the interaction with the communication tool is integrated into daily activities. By requiring conscious interaction from the user, the object will trigger reflection about new cultural routines and home routines (routines from the home country). The behavior of the object should trigger the owner of the tool to engage in an interaction with the product to find out more about the daily life of the other. By leaving the interaction open enough for interpretation, it can become possible for the sojourner to create his or her own language which can be used to communicate in a more ambiguous context (for example a signal that can be interpreted as "I am thinking about you").

\subsection{Implications}

When designing a new interactive communication tool, it is important to consider the implications on the behavior of the users, for example because of new obligations and privacy issues. These design recommendations aim at communicating details from a culture by sharing and comparing routines between the sojourner and the communication partner. Instead of the acculturation to routines in the new culture, it could happen that the sojourner tries to maintain his or her home routines. The interactive communication tool needs to be designed in such a way that it strikes a balance between the delight of recognizing home routines while also being triggered to explore new routines. By using asynchronous communication, the pressure of time-zone differences is limited. However, asynchronous communication requires attention to be divided between multiple communication moments for the sojourner and the communication partner. It is important to limit the new pressure created by this tool and to anticipate on the use of synchronous communication tools as well. When developing new interactive communication tools for people who favor high-context communication styles, it is important to consider that it might not be desired to share certain context information. Especially when designing for people from different cultures, it is important to remember that the perception of privacy might be different from our own. Above all, it should be clear which contextual information is shared and the user should have control over it.

\section{Circadian: an interactive communication tool based on recommendations}

The above-mentioned design recommendations led to the final design of the interactive communication tool named Circadian (pictured in Fig. 6). Similar to the Videomail object, this communication device is based on asynchronous video-messaging. The object can be used in two different modes, a decorative mode in which the object blends in the living room environment and the usage mode with which video messages can be viewed and recorded.

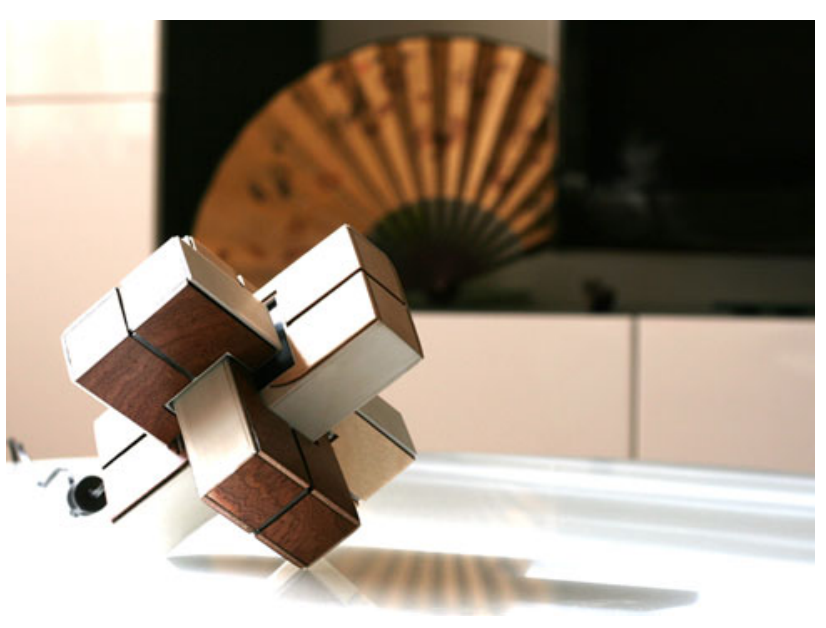

Fig. 6 The Circadian prototype shown as decoration

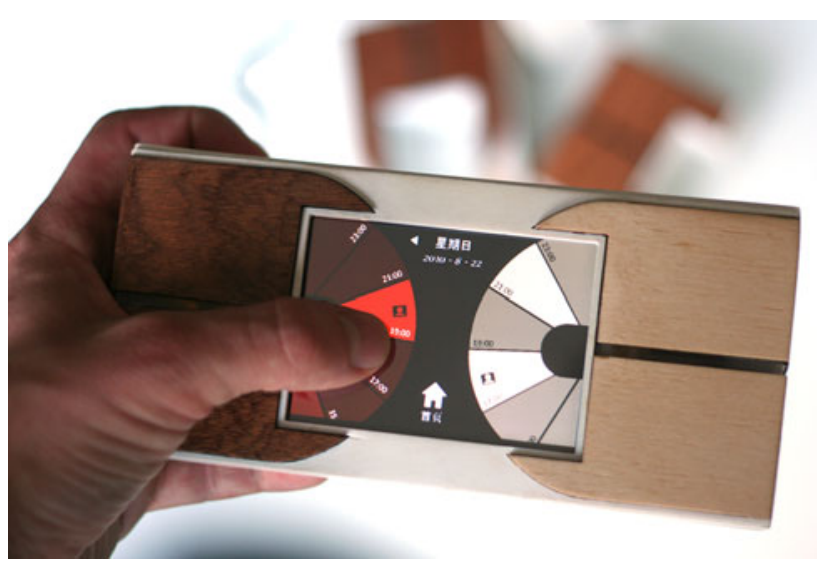

Fig. 7 Browsing through the day representation using the touch interface 
We will describe the object based on the design recommendations.

The target group Circadian was designed for consists of Chinese sojourners who moved to the Netherlands and their close relatives. It specifically supports the phase when the sojourner has recently moved and finds it valuable to maintain close family relations. The design is inspired by a Chinese puzzle: the Kong Ming Suo. Based on an architectural principle for attaching beams together, this device exists from three separate parts that combined form the device (Fig. 6). The materials chosen for the object symbolize the distance between the two different cultures. Mahogany wood for China based on traditional redwood and Beech wood to symbolize Northern European culture. The materials meet in the middle of the object, where the messages are hidden and cannot be seen when the object is in decorative mode. When the parts are separated, a touch display becomes visible (Fig. 7 shows the touch display)

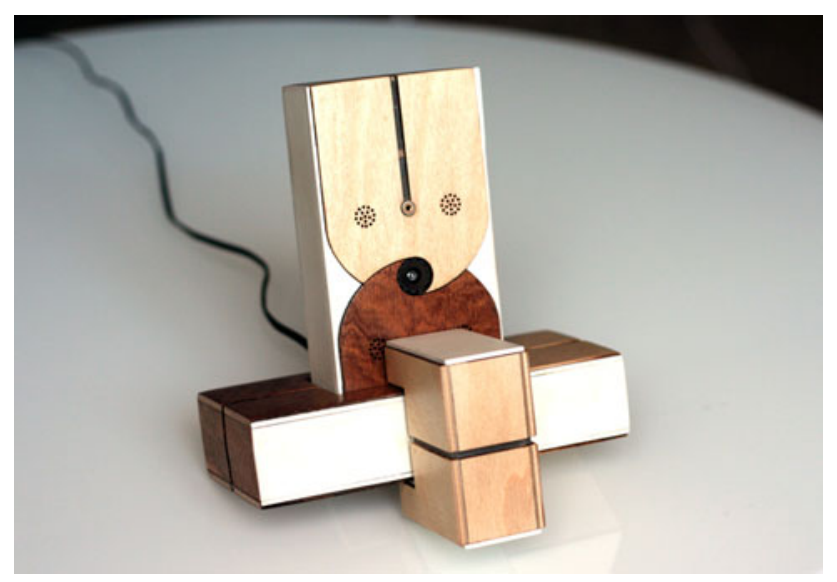

Fig. 8 Circadian in docked mode, for example for recording a video message

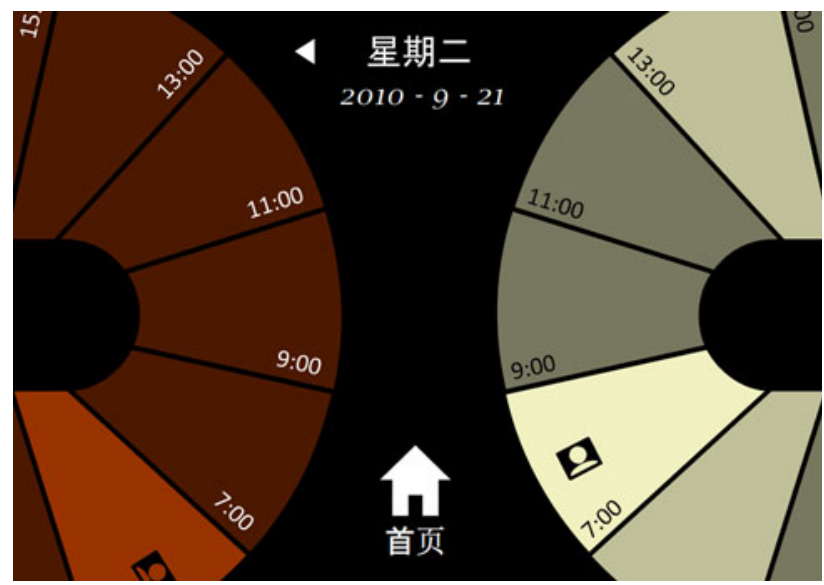

Fig. 9 The red disk represents the day of the Chinese family member, white of the sojourner which has a camera on the rearside (Fig. 8 shows the camera in the docking mode).

Aimed for sojourners who prefer high-context communication styles, we embedded context using two aspects: a visualization of the days of the two communication partners and video as medium for the messages. The overview of the day was built up by pieces representing time-intervals (this is visible in more detail in Fig. 9). The interface displays two of these day overviews, both in the local time of the user. We chose for the local-time perspective to make it easier for the users to compare each other's rituals and activities. Video messages are displayed on the moments they were recorded using a small icon which can be clicked. The communication partners can compare the video messages in the context of their day, which will give them extra input for $\mathrm{HC}$ communication.

To give an overview of communication routines, we used the color intensity of the time-interval to represent the usage of the object during the interval. Moving the object, interacting with the interface, viewing a movie or recording a movie, are all actions that will intensify the color of the time-interval. This visualization provides an overview of the routines of the interaction with the product, which creates opportunities for the communication partners to discover each other's routines and make it easier to create new communication routines.

The interaction and appearance of the product affords to be placed in the domestic environment. Our assumption is that this will result in a better integration of communication routines into daily life. Movements with the object will result in intensified colors in the interface, which functions both for communicating context and can be used to send ambiguous messages. To change from the decorative mode to the usage mode the user has to open the product, this action can be considered as a routine itself. This is both to protect the privacy of the users and also to transform the act of communication in a clear routine.

We considered implications of privacy by choosing for a dedicated object. The object does not register the environment autonomously, but requires an active interaction from the user. We chose an interface which will objectively show the usage of the local object and the remote object. By mapping these on a synchronized time-scale, we aimed at triggering reflection about the different lifestyles and the influence of culture.

\section{Concluding remarks}

In this paper, we studied how we can design for communication across cultures, in particular bridging ChineseDutch differences. We generated a set of design recommendations regarding target group, context, routines, 
interaction and implications, based on literature, a questionnaire study, interviews, and a technology probe. To validate these design recommendations, we created a final design facilitating communication across cultures, called Circadian. Of course, the studies we conducted have been mostly qualitative and with a limited amount of participants. Still, during the design of Circadian, we experienced the design recommendations to be abstract enough to leave space for creativity while providing a set of clear requirements which we used to base design decisions upon.

Acknowledgments We would like to thank all the participants who participated in the questionnaires, interviews and technology probe studies, in particular Kitty Miao and Yoyo Zhang from the China Plaza in Eindhoven for helping us to get in touch with all the participants.

Open Access This article is distributed under the terms of the Creative Commons Attribution Noncommercial License which permits any noncommercial use, distribution, and reproduction in any medium, provided the original author(s) and source are credited.

\section{References}

1. Herring C (1996) Computer-mediated communication: linguistic, social and cross-cultural perspectives. John Benjamins, Amsterdam

2. McLuhan M (1962) The Gutenberg galaxy: the making of typographic man. University of Toronto Press, Toronto

3. Andersen M (2008) Benefits survey for expatriates and globally mobile employees. Mercer LLC. http://www.mercer.com/ knowledgecenter/reportsummary.htm?idContent $=1326180$. Accessed 3 Oct 2011

4. Gardner D, Witherell D (2010) Record numbers of international students in U.S. higher education. Institute of International Education. http://www.iie.org/en/Who-We-Are/News-and-Events/ Press-Center/Press-Releases/2010/2010-11-15-Open-DoorsInternational-Students-In-The-US. Accessed 3 Oct 2011

5. Ward C, Bochner S, Furnham A (2001) The psychology of culture shock. Routledge, London

6. Oberg K (1960) Cultural shock: adjustment to new cultural environments. Pract Anthropol 7:177-182

7. Pantelidou S, Craig T (2006) Culture shock and social support. Soc Psychiatry Psychiatr Epidemiol 41(10):777-781

8. Adelman M (1988) Cross-cultural adjustment: a theoretical perspective on social support. Int J Intercult Relat 12(3):183-204

9. Sussman N (2000) The dynamic nature of cultural identity throughout cultural transitions: Why home is not so sweet. Pers Soc Psychol Rev 4(4):355-373

10. Kline S, Liu F (2005) The influence of comparative media use on acculturation, acculturative stress, and family relationships of Chinese international students. Int J Intercult Relat 29(4):367-390

11. Hofstede G (2001) Cultures consequences: comparing values, behaviors, institutions and organizations across nations. Sage Publications, Thousand Oaks

12. Triandis H (1988) Collectivism vs. individualism: a reconceptualization of a basic concept in cross-cultural psychology. In: Bagley C, Verma G (eds) Personality, cognition, and value: cross-cultural perspectives of childhood and adolescence. Macmillan \& Co, London

13. Schwartz S (1994) Beyond individualism/collectivism: new cultural dimensions of values. In: Kim U, Triandis H, Kagitcibasi C, Choi C, Yoon G (eds) Individualism and collectivism. Sage Publications, Thousand Oaks

14. Norton R (1978) Foundation of a communicator style construct. Hum Commun Res 4(2):99-112

15. Hall E (1976) Beyond culture. Random House, New York

16. Gudykunst W, Matsumoto Y, Ting-Toomey S, Nishida T, Kim K, Heyman S (1996) The influence of cultural individualism-collectivism, self construals, and individual values on communication styles across cultures. Hum Commun Res 22(4):510-543

17. Setlock L, Quinones P, Fussell S (2007) Does culture interact with media richness? The effects of audio vs. video conferencing on Chinese and American dyads. In: Proceedings of the 2007 40th annual Hawaii international conference on system sciences, pp 13

18. Kayan S, Fussell S, Setlock L (2006) Cultural differences in the use of instant messaging in Asia and North America. In: Proceedings of the 200620 th anniversary conference on computer supported cooperative work, pp 525

19. Setlock L, Fussell S (2010) What's it worth to you? In: Proceedings of the 2010 ACM conference on computer supported cooperative work, pp 341

20. Setlock L, Fussell S, Neuwirth C (2004) Taking it out of context. In: Proceedings of the 2004 ACM conference on computer supported cooperative work, pp 604

21. Daft R, Lengel R (1984) Information richness: a new approach to managerial behavior and organizational design. Res Organ Behav 6:191-233

22. Tee K, Brush A, Inkpen K (2009) Exploring communication and sharing between extended families. Int J Hum Comput Stud 67(2):128-138

23. Cao X, Sellen A, Brush A, Kirk D, Edge D, Ding X (2010) Understanding family communication across time zones. In: Proceedings of the 2010 conference on computer supported cooperative work, pp 155-158

24. Bossard J, Boll E (1950) Ritual in family living: a contemporary study. University of Pennsylvania Press, Philadelphia

25. Octavia J, van Den Hoven E, de Mondt H (2007) Overcoming the distance between friends. In: Proceedings of the 21th British HCI group annual conference, pp 79-82

26. IJsselsteijn W, Baren J, Markopoulos P, Romero N, De Ruyter B (2009) Measuring affective benefits and costs of mediated awareness: development and validation of the ABC-questionnaire. In: Markopoulos P, De Ruyter B, Mackay W (eds) Awareness systems. Springer, London, pp 473-488

27. Gaver W (2007) Cultural commentators: non-native interpretations as resources for polyphonic assessment. Int J Hum Comput Stud 65(4):292-305

28. Markopoulos P, Romero N, van Baren J, IJsselsteijn W, De Ruyter B, Farshchian B (2004) Keeping in touch with the family: home and away with the ASTRA awareness system. In: Extended abstracts of the 2004 conference on human factors in computing systems, pp 1351-1354

29. Mumford D (1998) The measurement of culture shock. Soc Psychiatry Psychiatr Epidemiol 33(4):149-154

30. Holtzblatt K, Wendell J, Wood S (2005) Rapid contextual design: a how-to guide to key techniques for user-centered design. Morgan Kaufmann, San Francisco

31. Mattelmäki T (2005) Applying probes: from inspirational notes to collaborative insights. CoDesign 1(2):83-102 